Proceedings

\title{
Edible Wild Flowers: An Innovative but Ancient Food †
}

\author{
Stefania Toscano, Valeria Rizzo *, Giuseppe Muratore and Daniela Romano
}

Citation: Toscano, S.; Rizzo, V.; Muratore, G.; Romano, D. Edible Wild Flowers: An Innovative but Ancient Food. Proceedings 2021, 70, 32. https://doi.org/10.3390/ foods_2020-07751

\section{Published: 10 November 2020}

Publisher's Note: MDPI stays neutral with regard to jurisdictional claims in published maps and institutional affiliations.

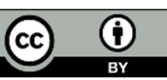

Copyright: $\left(C^{2} 2020\right.$ by the authors. Licensee MDPI, Basel, Switzerland. This article is an open access article distributed under the terms and conditions of the Creative Commons Attribution (CC BY) license (http://creativecommons.org/licenses/by/4.0/).
Department of Agriculture, Food and Environment [Di3A], University of Catania, Via Santa Sofia 100, 95123 Catania, Italy; stefania.toscano@unict.it (S.T.); g.muratore@unict.it (G.M.); dromano@unict.it (D.R.)

* Correspondence: vrizzo@unict.it

† Presented at the 1st International Electronic Conference on Food Science and Functional Foods, 10-25 November 2020; Available online: https://foods_2020.sciforum.net/.

\begin{abstract}
Edible flowers are often mentioned in connection with biologically active substances and their presence is today frequent in supermarkets. The main factor that determines their use is their appearance, so particular attention must be paid to the shelf life. Flowers must be protected from desiccation and their quality must be preserved. Thus, the aims of this study were to evaluate the shelf life of the spontaneous edible flowers Glebionis segetum, Malva sylvestris, and Tropaeolum majus and Papaver rhoeas, and to detect the presence of major polyphenols. The flowers were packaged with polypropylene (PP) bags and then stored in a refrigerator at $+4 \pm 1{ }^{\circ} \mathrm{C}$. Samples were tested in the dark and in the presence of light for 12 days. Gas composition, weight loss, and color were registered once the packages were opened; antioxidant activity, total phenols, and enzymatic analyses were performed. The light has a negative influence, the weight loss was limited, and the gas composition did not change significantly during shelf life, with variation in the studied samples. The highest variation in color parameters was found in control samples, whereas the extracts from G. segetum showed the highest antioxidant activity and polyphenol content; in addition, it was the most resistant but also had the highest weight loss. Furthermore, enzymatic results indicated the PP was the best packaging film if used in the dark. P. rhoeas was characterized by extreme fragility, $M$. sylvestris was not able to tolerate low temperatures, and T. majus changed its color progressively with time.
\end{abstract}

Keywords: visual quality; shelf life; lightening; color; reactive oxygen species (ROS); enzyme activity

\section{Introduction}

Edible flowers are highly perishable, with a short shelf life of 2-5 days after harvest. However, their market is becoming more important, as demonstrated by the increasing number of recipe books, magazine articles, and websites that encourage people to use them.

The potential number of suitable species is high (over 1000) and some species are also present in the spontaneous flora of the Mediterranean environment.

Due to their exotic aroma, delicate flavor, and visual appeal, the consumption of edible flowers is increasing. Thus, various types of edible flowers are purchased due to their health benefits because they are a good source of phytochemicals, including phenolic compounds [1].

As an example, the leaves of Tropaeolum majus (garden nasturtium) have been used in folk medicine to treat cardiovascular disorders, urinary tract infections, asthma, and constipation. Anticancer activity has been attributed to the extracts from the plant and recent studies have shown that the T. majus flowers are excellent sources of lutein and provitamin A and $\beta$-carotene [2]. T. majus is an herbaceous annual plant of the Tropaeolaceae family, a native plant of the Andes in South America, and its adaptability to different climates has helped its global dissemination. 
When plants are exposed to stress, reactive oxygen species (ROS), such as superoxide $\left(\mathrm{O}_{2}{ }^{-}\right)$, hydrogen peroxide $\left(\mathrm{H}_{2} \mathrm{O}_{2}\right)$, singlet oxygen $\left(\mathrm{O}_{2}\right)$, and hydroxyl radical $\left(\mathrm{OH}^{-}\right)$concentration, increase inside plant tissues [3]. Resistant plants usually use antioxidants to reduce the detrimental effects on plant cells. In addition, enzymes such as catalase (CAT), glutathione peroxidase (GPX), superoxide dismutase (SOD), and others that exist in the cells are used to scavenge ROS [4].

The unavoidable exposure to light during the time that edible flowers are on sale influences the evolution of the quality parameters of this product, producing stress in vegetable cells. The influence of light on the quality of minimally processed vegetables has been demonstrated, either for the effect on synthesis or changes in pigments, or on the metabolic activity of the packaged product, which makes exposure to light a determining factor in their shelf life [5].

Based on the above, the aim of the study was to understand the shelf life of Glebionis segetum, Malva sylvestris, Tropaeolum majus and Papaver rhoeas edible flowers, looking at chemical and qualitative characteristics, in addition to enzymatic changes in their charge due to storage conditions.

\section{Methods}

Wild flowers were picked in the rural areas surrounding the urban area of Catania. Flowers were selected and then placed in polyethylene terephthalate (PET) trays. Each tray was packed in an ordinary atmosphere using polypropylene (PP) films with oxygen transmission rate (OTR) 20,000 cc/m²/24 h), and macro perforated PP was used as control (C). Samples were stored in two refrigerators at $+4 \pm 1{ }^{\circ} \mathrm{C}$; one was kept in the dark, while the second was with an internal light produced by a "COLD LIGHT 6500 K" LED lamp, to simulate sales conditions.

The headspace gas composition and fresh weight loss (FWL) were expressed as reported by Rizzo et al. [6]. Analysis was conducted on three replicates at each sampling time. Each package was labeled and weighed at the beginning of the storage period and then at each sampling time $(3,6,9$ and $12 \mathrm{~d})$, and weighed before opening the container for further analysis. Color was measured by a digital camera, and images processed using Image-Pro ${ }^{\circledR}$ Plus 7.0 software (Media Cybernetics 70 Inc., Rockville, MD, USA). Extracts were obtained according to Pires et al. [7], and the determinations of total phenol content (TPC) and antioxidant activity (AA) were determined following, respectively, the previous studies of Gonzalez et al. [8] and Hatano et al. [9], with slight modifications.

The SOD (SOD; EC 1.15.1.1) activity was assayed by monitoring the inhibition of photochemical reduction of Nitro Blue Tetrazolium (NBT) according to the method of Giannopolitis and Ries [10]. The CAT (CAT; EC 1.11.1.6) was analyzed according to Aguilera et al. [11]. The GPX (GPX; EC 1.11.1.7) activity was measured using the method described by Ruley et al. [12].

Analyses were carried out on three replicates at each sampling time. All results were presented as the mean \pm S.E. The statistical analyses were performed using CoStat version 6.311 (CoHortSoftware, Monterey, CA, USA); one-way ANOVA was used. The differences between the means were determined using Tukey's test $(p<0.05)$.

\section{Results and Discussion}

The light radiation emitted by the lamps used in the controlled temperature cells had the following technical characteristics: visible 4800 VIS (lux); 20.02 RAD, 0 UVA, 0.2 UVB, 1.4 UVC ( $\left.\mathrm{W} \mathrm{m}^{-2}\right) ; 124.6$ PAR ( $\left.\mu \mathrm{mol}\right)$. Results are reported as Light PP or $\mathrm{C}$ when samples were stored under light and in PP film or as Control without any plastic film, and Dark $\mathrm{PP}$ or $\mathrm{C}$ for samples stored in the dark in the same packaging conditions reported above.

All plant products, including edible flowers, are subject to natural weight loss, which is greater the higher their respiration rate. Although many previous papers have studied nutritional composition of edible wild flowers $[7,13,14]$, no studies of their shelf life were 
found, especially relating to weight loss, respiration rate, or color parameters; moreover, in cited papers the wide variety of available flowers makes it difficult to make a comparison among them. All flowers finished their shelf life at 9 days (Figure 1). G. segetum was the heaviest flower, and the higher decrease was observed at just after 3 days, in samples stored under Light in PP films (88\%), whereas the Light control was similar to Dark PP $(62 \%)$ with the only exception after 3 days. The M. sylvestris kept under Light control reached a loss of $68 \%$, whereas the same samples stored in Dark PP film saved the $42 \%$ of the starting weight. In T. majus the differences between light and dark storage were less evident with samples kept under Light in PP showing a 25\%-30\% higher weight loss than both samples stored in the Dark, although the differences were not statistically significant. $P$. rhoeas petals are thin and sensitive, and changes were not statistically significant (Figure 1).



Figure 1. Effect of the packaging during the 12 days of storage on the weight loss (\%) of G. segetum, $M$. sylvestris, T. majus, and $P$. rhoeas. Values are means $\pm \mathrm{SE}(n=3)$. Columns denoted with the same letters are not significantly different, as determined by Tukey's test $(p<0.05)$.

In Figure 2, the concentrations of $\mathrm{CO}_{2}$ of packed samples are reported. The PP film allows some exchange of $\mathrm{CO}_{2}$ with the external atmosphere, so what can be observed in G. segetum is that the $\mathrm{CO}_{2}$ concentration is always higher in samples kept in the Dark; the same trend is evident in M. sylvestris, whereas the opposite was detected in T. majus and $P$. rhoeas samples under Light. The color is an important organoleptic property of edible flowers. Figure 3 shows the color parameters that changed more during the study; in particular, the intensity of the color for G. segetum and M. sylvestris appeared more stable, whereas the hue (the correct word to use to refer to just the pure spectrum colors) for $T$. majus and $P$. rhoeas showed the highest changes, especially in samples under Light. The TPC was higher in G. segetum $(1.56 \pm 0.44 \mathrm{mg} / 100 \mathrm{~g})$ and smaller in P. rhoeas $(0.92 \pm 0.46$ $\mathrm{mg} / 100 \mathrm{~g}$ ), which was more similar among the other flowers with a medium value of 0.94 $\pm 0.42 \mathrm{mg} / 100 \mathrm{~g}$. TPC results were confirmed by AA for the G. segetum, with the highest value of $79.55 \pm 17.7 \%$, whereas the lowest AA\% was obtained by M. sylvestris (55.86 \pm 9.5 ).

In edible flowers and derived products, the activity of some enzymes affects their quality [15]. The light severely damaged the petals of all species; under these conditions, the flowers did not reach the twelfth day. SOD, CAT, APX, and GPX are important enzymes that play a crucial role in antioxidant defense. ROS accumulation causes oxidative injury, accelerating senescence progression and various senescence-associated disorders. 
The results showed that the CAT activity decreased in M. sylvestris and P. rhoeas PP Dark at the end of the trial. No significant differences were found between treatments in $T$. majus and G. segetum (Figure 4A). Balasundram et al. [16] reported that plants cope with stress by stimulating the formation of polyphenols and antioxidant activities. The GPX activity showed highest values in G. segetum and P. rhoeas PP compared to Control flowers (Figure 4B). Increase in SOD activity was observed in M. sylvestris and G. segetum PP. Opposite trends were found in the other two species (Figure 4C). An increased level of SOD suggests a plant protective mechanism against oxidative stress [17]. To counteract the oxidants, the antioxidant system attempts to boost endogenous antioxidants to protect cells from oxidative damage, which includes antioxidant enzymes such as SOD and GPX [18].
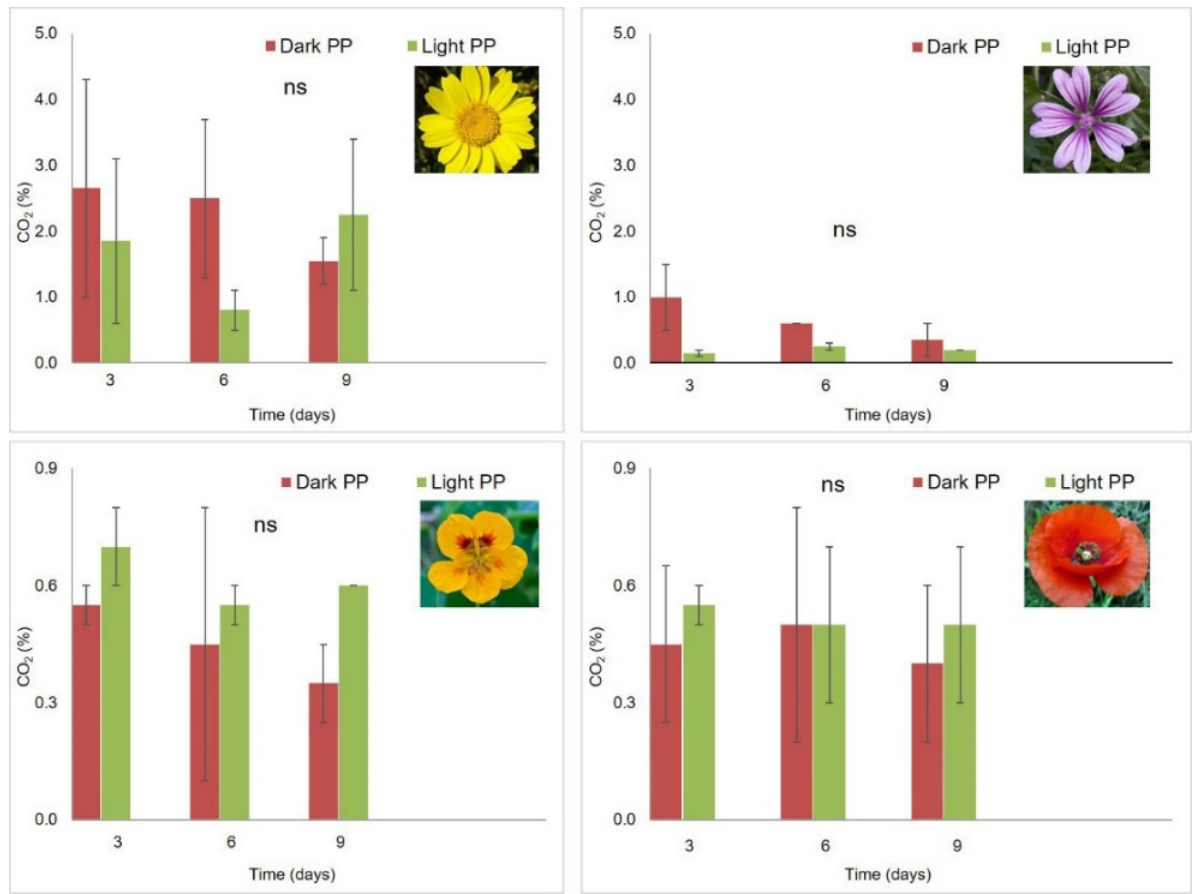

Figure 2. Carbon dioxide respiration rate during the 12 days of storage of G. segetum, M. sylvestris, $T$. majus and $P$. rhoeas. Values are means $\pm \mathrm{SE}(n=3)$. Columns denoted with the same letters are not significantly different, as determined by Tukey's test $(p<0.05)$.

The results showed that the extract of G. segetum inhibits the increase in oxidative stress, characterized by the elevation of SOD and GPX levels. The scavenging capacity diminished during flower conservation due to the decrease in antioxidant enzyme activity and high ROS accumulation. This suggests that the balance between ROS production and antioxidant enzyme activity was destroyed, causing extensive senescence of flower tissues [19]. 


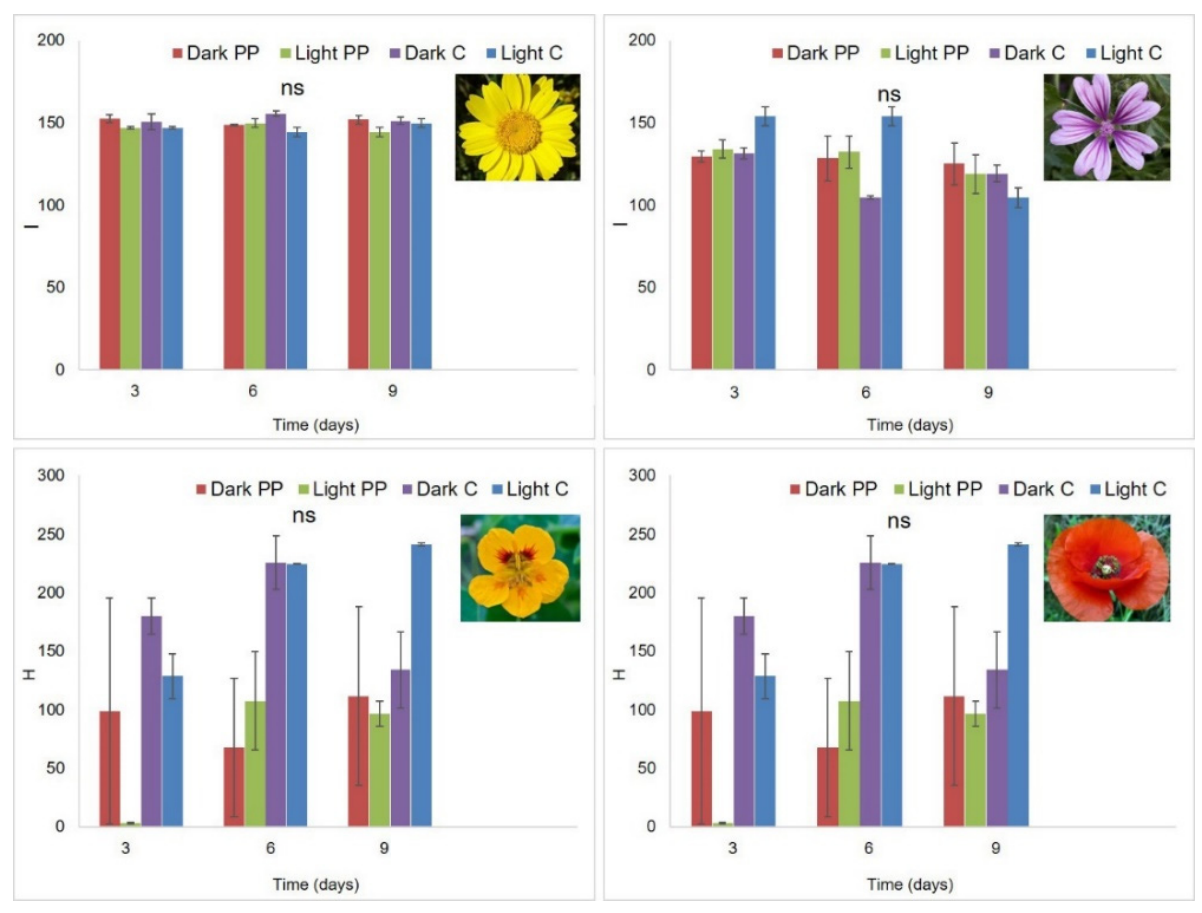

Figure 3. Effect of the packaging on color parameter intensity and hue during the 12 days of storage of G. segetum, M. sylvestris, T. majus and P. rhoeas. Values are means \pm SE $(n=3)$. Columns denoted with the same letters are not significantly different, as determined by Tukey's test $(p<0.05)$.
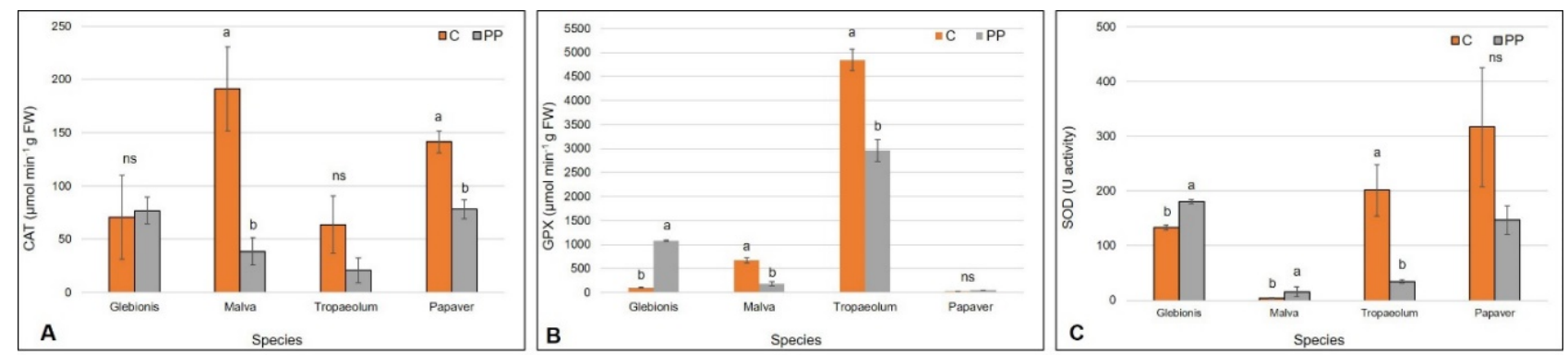

Figure 4. Effect of the packaging at the end of the trial on catalase (CAT) (A), glutathione peroxidase (GPX) (B), and superoxide dismutase (SOD) (C) activity in flowers of G. segetum, M. sylvestris, T. majus and P. rhoeas. Values are means \pm SE $(n=3)$. For each species, columns denoted with the same letters are not significantly different, as determined by Tukey's test $(p<0.05)$.

\section{Conclusions}

In conclusion, edible wild flowers are highly perishable, compared with other types of flowers, because their stems are cut very short and they are stored without additional water supply. PP packaging and refrigerated storage in the dark are the best solutions to keep the highest quality for 9 days, although weight loss could be severe in G. segetum and light-damaged $P$. rhoeas and T. majus. TPC and AA measured at the beginning of the study were related with the diminishing scavenging capacity observed after 9 days, resulting from the stress caused by conservation and measurable with the increase in ROS.

Author Contributions: methodology, formal analysis, data curation, writing-original draft preparation S.T. and V.R.; investigation, D.R.; resources, writing - review and editing, supervision, D.R. and G.M. All authors have read and agreed to the published version of the manuscript.

Funding: This research received no external funding

Institutional Review Board Statement: Not applicable.

Informed Consent Statement: Not applicable 
Data Availability Statement: Main data are contained within the article; further data presented in this study are available on request from the corresponding author.

Acknowledgments: Authors would like to thank Beatrice Messina for providing wild flowers from the rural areas surrounding the urban area of Catania.

Conflicts of Interest: The authors declare that there are no conflicts of interest.

\section{References}

1. Fernandes, L.; Casal, S.; Pereira, J.A.; Saraiva, J.A.; Ramalhosa, E. Edible flowers: A review of the nutritional, antioxidant, antimicrobial properties and effects on human health. J. Food Comp. Anal. 2017, 60, 38-50, doi:10.1016/j.jfca.2017.03.017.

2. Benyelles, B.; Allali, H.; Fekih, N.; Touaibia, M.; Muselli, A.; Djabou, N.; El Amine Dib, M.; Tabti, B.; Costa, J. Chemical Composition of the Volatile Components of Tropaeolum majus L. (Garden Nasturtium) from North Western Algeria. PhytoChem BioSub J. 2015, 9, 92.

3. Diao, Q.; Song, Y.; Qi, H. Exogenous spermidine enhances chilling tolerance of tomato (Solanum lycopersicum L.) seedlings via involvement in polyamines metabolism and physiological parameter levels. Acta Physiol. Plant. 2015, 37, $230-245$.

4. Rasool, S.; Ahmad, A.; Siddiqi, T.O.; Ahmad, P. Changes in growth, lipid peroxidation and some key antioxidant enzymes in chickpea genotypes under salt stress. Acta Physiol. Plant. 2013, 35, 1039-1050.

5. Sanz, S.; Olarte, C.; Ayala, F.; Ech'Avarri, J.F. Evolution of quality characteristics of minimally processed asparagus during storage in different lighting conditions. J. Food Sci. 2009, 74, 6.

6. Rizzo, V.; Lombardo, S.; Pandino, G.; Barbagallo, R.N.; Mazzaglia, A.; Restuccia, C.; Mauromicale, G.; Muratore, G. Shelf life study of ready to cook slices of globe artichoke 'Spinoso sardo': Effects of anti-browning solutions and edible coating enriched with "Foeniculum vulgare" essential oil. J. Sci. Food Agric. 2019, 99, 5219-5228.

7. Pires, T.C.S.P.; Dias, M.I.; Barros, L.; Ferreira, I.C.F.R. Nutritional and chemical characterization of edible petals and corresponding infusions: Valorization as new food ingredients. Food Chem. 2017, 220, 337-343.

8. Gonzalez, I.; Barrio, R.; Valverde, V.; Ortín, A.; Periago, M. Nutritional Composition and Antioxidant Capacity in Edible Flowers: Characterisation of Phenolic Compounds by HPLC-DAD-ESI/MSn. Int. J. Molec. Sci. 2014, 16, 805-822.

9. Hatano, T.; Kagawa, H.; Yasuhara, T.; Okuda, T. Two new flavonoids and other costituents in Licorice root: Their relative astringency and radical scavenging effects. Chem. Pharm. Bull. 1988, 36, 2090-2097.

10. Giannopolitis, C.N.; Ries, S.K. Superoxide Occurrence in Higher Plants. Plant Physiol. 1977, 59, $309-314$.

11. Aguilera, J.; Bischof, K.; Karsten, U.; Hanelt, D.; Wiencke, C. Seasonal Variation in Ecophysiological Patterns in Macroalgae from an Arctic Fjord. II. Pigment Accumulation and Biochemical Defense Systems against High Light Stress. Mar. Biol. 2002, 140, 1087-1095.

12. Ruley, A.T.; Sharma, N.C.; Sahi, S.V. Antioxidant Defense in a Lead Accumulating Plant. Sesbania drummondii. Plant Physiol. Bioch. 2004, 42, 899-906.

13. Li, A.-N.; Li, S.; Li, H.-B.; Xu, D.-P.; Xu, X.-R.; Chen, F. Total phenolic contents and antioxidant capacities of 51 edible and wild flowers. J. Funct. Foods 2014, 6, 319-330.

14. Chen, G.-L.; Chen, S.-G.; Xie, Y.-Q.; Chen, F.; Zhao, Y.-Y.; Luo, C.-X.; Gao, Y.-Q. Total phenolic, flavonoid and antioxidant activity of 23 edible flowers subjected to in vitro digestion. J. Funct. Foods 2015, 6, 243-259.

15. Hogan, E.; Kelly, A.L.; Sun, D.-W. High pressure processing of foods: An overview. In Emerging Technologies for Food Processing; Da-Wen, S., Ed.; Elsevier: California, CA, USA, 2005; pp. 3-32.

16. Balasundram, N.; Sundram, K.; Samman, S. Phenolic compounds in plants and Agri-industrial by-products: Antioxidant activity, occurrence, and potential uses. Food Chem. 2006, 99, 191-203.

17. Faisal, M.; Anis, M. Effect of light irradiations on photosynthetic machinery and antioxidative enzymes during ex vitro acclimatization of Tylophora indica plantlets. J. Plant Interact. 2010, 5, 21-27.

18. Zhang, Y.-J.; Gan, R.-Y.; Li, S.; Zhou, Y.; Li, A.-N.; Xu, D.-P.; Li, H.B. Antioxidant phytochemicals for the prevention and treatment of chronic diseases. Molecules 2015, 20, 21138-21156.

19. Zhang, Y.; Luo, Y.; Wang, X.; Chen, Q.; Sun, B.; Wang, Y.; Liu, Z.; Tang, H. Variation in bioactive compounds, antioxidant enzymes and radical-scavenging activity during flower development of Rosa hybrid. AIP Conf. Proc. 2018, $1956,020021$. 